\title{
Assessing the European wastewater reclamation and reuse potential - a scenario analysis
}

\author{
Rita Hochstrat ${ }^{\mathrm{a}}$, Thomas Wintgens ${ }^{\mathrm{a} *}$, Thomas Melin $^{\mathrm{a},}$ Paul Jeffrey $^{\mathrm{b}}$ \\ a Department of Chemical Engineering, RWTH Aachen University, 52056 Aachen, Germany. Tel: +49 \\ 24180 96233, Fax: -49 8092252, E-mail: wintgens@ivt.rwth-aachen.de,) \\ b School of Water Science, Cranfield University, Cranfield, United Kingdom, Tel: +44 1234 754814, \\ Fax: +44 1234 751671E-mail: p.j.jeffrey@cranfield.ac.uk \\ *Corresponding author
}

\begin{abstract}
This paper presents a model-based estimation of the wastewater reclamation and reuse potential in a European context. The effects of different water management scenarios on the appraisal is quantified. Impacts of climate change on water availability and variation in the demand pattern and water use of considered countries are the modifying variables in these scenarios. The simulation points out that there is a significant potential for an increased utilisation of reclaimed wastewater in many European countries, specifically in the Mediterranean region. Aspects related to the factors which will definitely drive or slow down the development are addressed.
\end{abstract}

Keywords: Integrated water management; potential estimation; wastewater reclamation and reuse, scenario analysis, water availability

\section{Introduction}

Wastewater reuse has developed from a basic method of disposing wastewater without any treatment to an often highly engineered technique of wastewater upgrading and water resources augmentation in water scarce regions throughout the world.

Due to limited water resources, typically water stressed countries in dry climates like Australia, Israel and the State of California have developed wastewater reuse strategies and programmes acknowledging the beneficial role wastewater reuse can play in integrated water management [1-3].

The water stress situation in Europe is illustrated in Figure 1, revealing that most countries exhibit a water stress index (a country's ratio of water abstraction to total renewable freshwater resources) of less than $20 \%$. Italy, Germany and Spain range between $20 \%$ and $30 \%$, whereas Belgium, Bulgaria, Malta and Cyprus exceed $40 \%$. The population of the countries of these two categories makes up approximately 200 million people. 


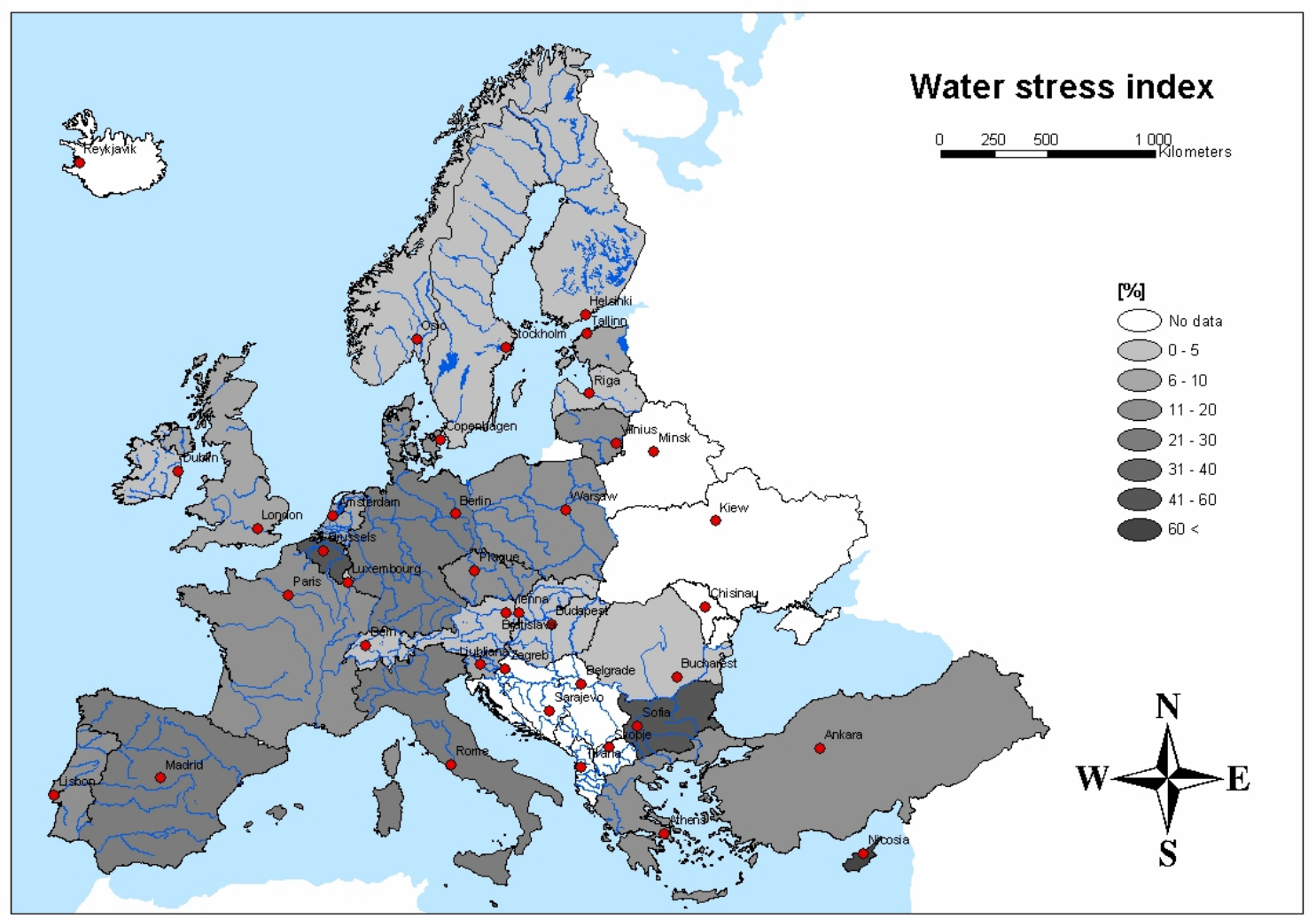

Figure 1: Water stress index for European countries in 2000 (Map provided by [4])

Parallel to increasing severity and frequency of droughts experienced in the early 1990s and in summer 2003, sustainable use of water resources gains more and more importance.

In the water policy frame this issue has been incorporated into the Water Framework Directive (WFD - 2000/60/EC). Enacting the WFD, the European Union established an environmental policy which aims at achieving a good status of surface water and groundwater in terms of quality and quantity. This will promote a sustainable water resources utilisation and might favour wastewater reclamation and reuse as a viable option. But, on the European level, there are no legislative regulations concerning wastewater reuse so far, apart from the Urban Wastewater Treatment Directive (91/271/EEC - UWWTD) which advises to reuse wastewater "whenever appropriate”.

Thus the installation of wastewater reuse schemes across Europe has been carried out under country specific national or even regional guidance. Additionally, wastewater reuse potential estimates presented in the literature often exclusively cover particular regions or countries and are presented without any reference to quantification methods applied to derive the appraisal [5, 6].

The basic aim of this paper is to present an approach to quantitatively assess the potential of municipal wastewater reclamation and reuse in Europe taking into account possible changes of today's circumstances and their impact on the projected reuse potential.

\section{Model development}

The estimation of water reuse potential in Europe presented in this paper is based on a mathematical representation of that share of water demand and supply which can be covered by reclaimed wastewater. (A more detailed explanation of the model development was presented at the IWA Conference in Marrakech, September 2004 [7]). 
The model is based on a straightforward mass balance approach describing the volumetric flow of reused wastewater $Q$ in a particular spatial or temporal context at an equilibrium point of supply and use of reclaimed wastewater. The basic model equation for the assumption of reuse in different sectors is structured as follows:

$$
E \cdot \eta=U \cdot \phi=\sum U_{i} \cdot \phi_{i}=Q \Rightarrow Q=\frac{1}{2} \cdot\left(E \cdot \eta+\sum U_{i} \cdot \phi_{i}\right)
$$

quation 1)

E : Effluent of wastewater treatment plants $\left[\mathrm{Mm}^{3} / \mathrm{a}\right]$

$\mathrm{U}$ : Total water demand $\left[\mathrm{Mm}^{3} / \mathrm{a}\right]$

$\mathrm{U}_{\mathrm{i}}$ : Use of water in a specific sector i $\left[\mathrm{Mm}^{3} / \mathrm{a}\right]$

$\mathrm{Q}$ : Volumetric flow of reused wastewater $\left[\mathrm{Mm}^{3} / \mathrm{a}\right]$

$\eta$ : Fraction of wastewater reclaimed, hereafter reclamation-factor [-]

$\phi$ : Fraction of total demand covered by reclaimed water, hereafter reuse-factor [-]

$\phi_{\mathrm{i}}$ : Fraction of demand covered by reclaimed water in a sector i [-]

\subsection{Determination of variables}

To calculate a change in the total wastewater reuse volume during a time interval, the current wastewater treatment capacity $E$, the fraction reclaimed $(\eta)$ and reused $(\phi)$ and the sectoral water demand $(U)$ have to be known. Data on sectoral water use and treated effluents were extracted from the EUROSTAT database, the FAO AQUASTAT database and various national statistics. Information on wastewater reclamation and reuse $(Q)$ is based on literature survey and the compilation of installations conducted by Bixio et al. [8].

Based on this data collection the current values for both the wastewater reclamation and the reuse factor for a particular country were calculated. As water stress is regarded as a main driving mechanism behind wastewater reclamation and reuse a correlation between the above mentioned factors and a country's water use practice was investigated. In order to emphasise the different impacts of sectoral water uses, each was weighted according to its consumptive character thus deriving the term of consumptive water use intensity $A$ ' according to the following equation:

$$
A^{\prime}=\frac{U_{A G R} \cdot 0.77+U_{P W S} \cdot 0.18+U_{I N D} \cdot 0.14+U_{E L E} \cdot 0.14}{\text { Total renewable freshwater resources }} \quad \text { (Equation 2) }
$$

$A^{\prime}$ : Consumptive water use intensity

$U_{A G R}$ : Water abstraction for agricultural use [ $\left.\mathrm{Mm}^{3} / \mathrm{a}\right]$

$U_{P W S}$ : Water abstraction for public water supply [ $\left.\mathrm{Mm}^{3} / \mathrm{a}\right]$

$U_{I N D}$ : Water abstraction for industrial uses [ $\left.\mathrm{Mm}^{3} / \mathrm{a}\right]$

$U_{E L E}$ : Water abstraction for electricity generation $\left[\mathrm{Mm}^{3} / \mathrm{a}\right]$

The sectoral conversion factors were adopted from [9].

Eventually, a correlation between consumptive water use intensity and both factors was established and mathematically modelled by an empirical function, which proved to be most appropriate in representing the type of observed relationship (cf. Figure 2). 


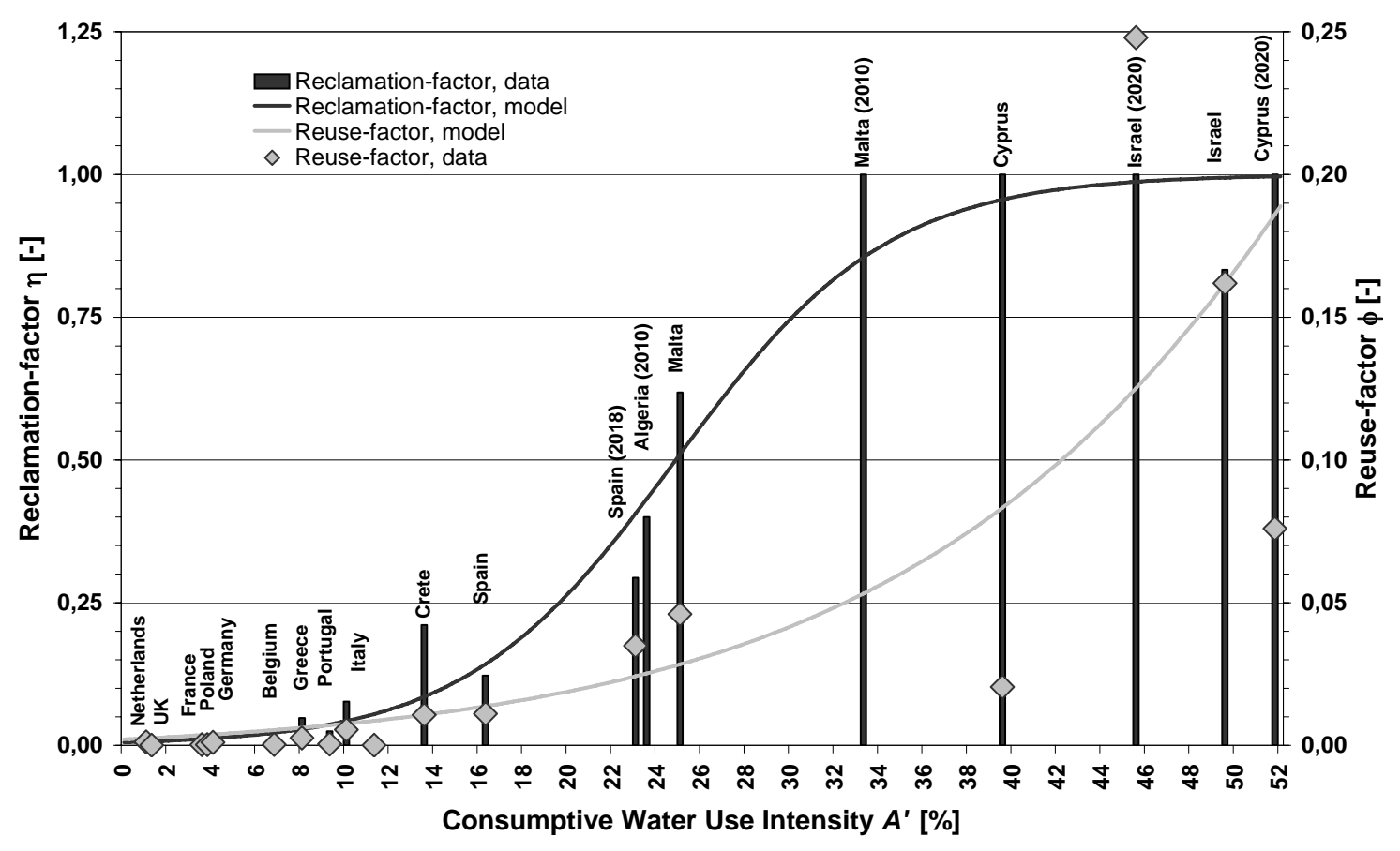

Figure 2: Correlation of reclamation- and reuse-factor and consumptive water use intensity

\subsection{Scenario description}

The established model implies that any deterioration of water availability or increase in water demand will enforce a change of the consumptive water use intensity, that on itself modifies both the wastewater reclamation- and reuse-factor, hence the reused wastewater flow $Q$. In order to depict the impact of decreasing water availability and increasing water demand different scenarios were tested. The assumptions for each scenario are summarised in Table 1.

First, the possible decline of water availability due to climate change was appraised referring to the results of the EuroWasser model by Lehner et al. [10]. This model is forecasting the impact of climate change on water availability in Europe for the time horizons 2020s and 2070s. Due to their calculations some river basins will have to cope with heavily reduced water availability. Decreases of more than $10 \%$ are projected for some continental countries (Poland, Hungary) and South Eastern countries (Bulgaria, Romania, parts of Turkey) whereas most South European countries will suffer from shortenings of $25 \%$ and more. The First European Climate Assessment [11] came to similar conclusions predicting a reduction of the mean annual flow in Portuguese river basins of $10 \%$ to $20 \%$. Hence the reductions of water availability for the water shortage scenarios III and IV were based on assumptions in these orders of magnitude.

Changes in water demand were estimated to the following premises. As, in general, irrigated agriculture is much more productive than rain fed cultivation [12] the resumption and enforcement of irrigation practice in most of the eastern European countries was assumed. In addition, planned extensions of irrigated land in Spain and Portugal were taken into account $[5,13]$.

Table1: Different scenarios and underlying basic conditions

\begin{tabular}{|c|c|c|c|c|}
\hline Scenario & I & II & III & IV \\
\hline Projection year & & & & \\
\hline
\end{tabular}


Water availability

Treated wastewater

General

characterisation

Water demand
Constant (ltaa 1961-1990)

changes due to population

growth

constant specific water

demand ELE: water use for electricity
ltta: long term annual average

An improvement of the electricity supply in the Accession Countries entailed by increasing demand and economic recovery will demand additional water resources or might at least cause conflicts between competing water uses.

The domestic water demand per capita is considered invariant. This causes changes of public water supply sector's water demand according to population growth and connection rates.

The overall resulting changes of consumptive water use intensity for the different scenarios are listed in Table 2.

Table 2: Consumptive water use intensity for different scenarios [\%]

\begin{tabular}{lccccc}
\hline Country & Status 2000 & Scenario I & Scenario II & Scenario III & Scenario IV \\
\hline Cyprus & 39.6 & 51.9 & 51.9 & 57.7 & 69.1 \\
Israel & 49.5 & 45.3 & 45.4 & 50.5 & 60.6 \\
Malta & 25.0 & 25.5 & 30.2 & 33.5 & 40.2 \\
Bulgaria & 8.1 & 14.8 & 23.8 & 27.6 & 33.2 \\
Spain & 16.3 & 16.3 & 22.9 & 25.5 & 30.6 \\
Italy & 9.8 & 9.8 & 14.7 & 16.3 & 19.5 \\
Turkey & 11.2 & 11.4 & 11.6 & 12.9 & 15.5 \\
Portugal & 9.1 & 9.2 & 10.5 & 11.6 & 14.0 \\
Greece & 8.1 & 8.0 & 10.1 & 11.2 & 13.4 \\
Belgium & 6.7 & 6.1 & 6.1 & 7.5 & 9.0 \\
Poland & 3.7 & 3.7 & 3.7 & 5.7 & 6.9 \\
France & 3.6 & 4.6 & 4.5 & 5.1 & 6.1 \\
Denmark & 4.5 & 4.5 & 4.5 & 5.0 & 6.1 \\
Germany & 3.9 & 4.0 & 4.0 & 4.5 & 5.4 \\
Romania & 0.8 & 0.8 & 2.1 & 2.3 & 2.8 \\
UK & 1.2 & 1.3 & 1.3 & 1.4 & 1.7 \\
Netherlands & 1.0 & 1.1 & 1.1 & 1.2 & 1.4 \\
Hungary & 1.0 & 1.0 & 1.0 & 1.1 & 1.3 \\
\hline
\end{tabular}

As expected, the scenarios easily cause an increase of the consumptive water use intensity for all countries by up to one third. Cyprus, Spain, Malta, Portugal, Italy and Bulgaria even experience an intensification of water stress by $50 \%$ to $100 \%$ culminating in consumptive water use intensities between $14 \%$ and $69 \%$. 
Obviously the level and thus the deterioration of water stress various remarkably between the countries. Entailed to these changes not only the impacts of water stress will aggravate but also the number of affected people in Europe.

\section{Results}

The current status of wastewater reuse in some European countries and the projected wastewater reuse potential according to the model calculations and scenario assumptions are both depicted in Figure 3.

The simulation points out that there is a significant potential for an increased utilisation of reclaimed wastewater in many European countries, specifically in the Mediterranean region.

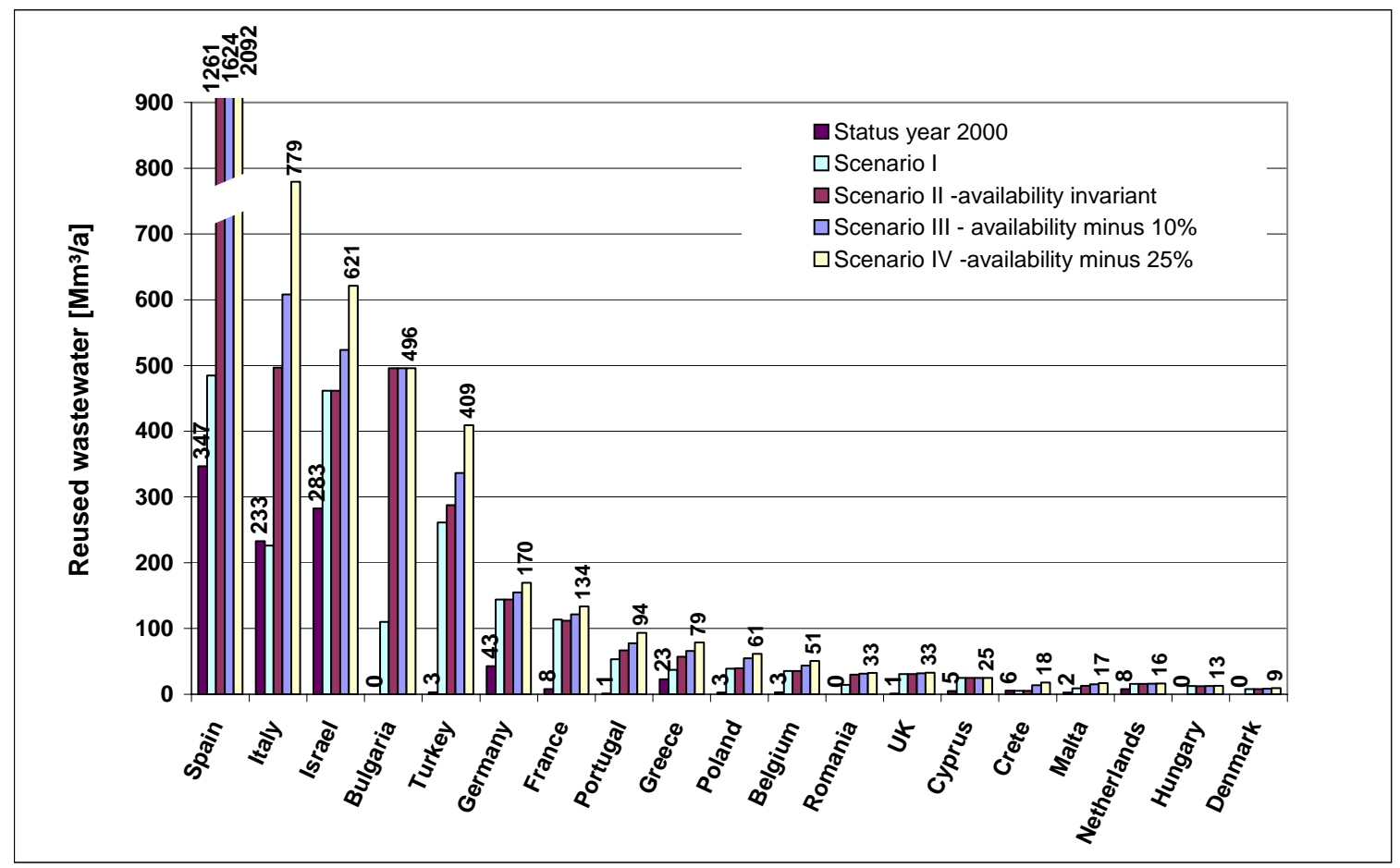

Figure 3: Estimated wastewater reuse potential under different scenario conditions

Spain shows by far the highest projected reuse potential, which is supposed to triple (Scenario II) or even grow six-fold compared to today's practice reaching a maximum of 2,000 $\mathrm{Mm}^{3} / \mathrm{y}$.

Similar increases are illustrated for Italy, Portugal, Greece and Turkey primarily caused by a combined effect of high irrigation demand and reduced water availability. Even countries like Germany, Poland and the UK are supposed to develop their wastewater reuse practice under water shortage conditions.

Not only the total amount of reclaimed water but also its substitution potential with respect to a country's water management varies remarkably among the considered countries. According to the model outcome, the demand coverage rate, i.e. the ratio of reused effluent to the total water abstraction $(\mathrm{Q} / \mathrm{U})$, ranges from $17 \%$ to $30 \%$ in Israel and Malta and amounts to $3 \%$ - $7 \%$ in Cyprus and Spain.

On the whole, the reused wastewater volume would save between $1.0 \%$ and 1.5 $\%$ of total water abstraction of European countries (including Israel) in the year 2025. This is close to estimations for the USA, that project a substitution of $1.5 \%$ of total freshwater abstraction by wastewater reuse in the year 2000 (Kamizoulis et al., 2003) [14]. 


\section{Conclusions}

The scenario analysis presented in this paper reveals an over-proportionate increase in wastewater reuse potential with declining water availability in most European countries. An average water availability curtailment of $25 \%$ on a country level can already result in tremendous wastewater reuse potential increase. Any aggravation of water restriction might consequently promote the reuse of wastewater. Therefore, the results presented in this paper may only serve as a yardstick. Water shortage might be much more severe than is expressed by the long term annual average which is just a very rough figure characterising a country's water availability. It does not take into account the uneven spatial and temporal distribution and thus the efforts it might already take to balance demand and supply on a regional level. The coverage of seasonal demand peaks, e.g. for irrigation or public water supply in tourist regions, involves the risk of aquifer over exploitation [15] if no abstraction restrictions or price incentives are asserted.

In addition, a series of dry years can easily push the average annual rainfall below any long term average. Recent declines in average precipitation compared to the 19601990 ltta are reported for several countries $[16,17,18]$.

Moreover, a reduction of water availability is often caused by inappropriate quality of water resources (brackish groundwater due to saltwater intrusion) as well as by stipulated abstraction or supply restrictions for certain users. Such trends might cause even more severe decreases in water availability than assumed in the scenario presented here.

Nonetheless, the results do raise but naturally leave open the question how to accompany the realisation of this massive potential from a regulatory point of view and how to shape an appropriate framework of incentives and implementation support measures.

The potential utilisation shall not contradict the "whenever appropriate" claim of the Urban Wastewater Treatment Directive, thus demanding the determination of appropriateness. To date, appropriateness has often been described primarily with regard to entailed health risk prevention hence aiming at the establishment of limit values for certain substances or even comprehensive risk assessment and management practices.

These aspects will be of paramount importance for the wastewater potential realisation in applications that could absorb huge volumes of water but are at the same time sensitive to health objections, as for example groundwater recharge.

In other cases, switching from conventional water resources to reclaimed wastewater is primarily hindered by cost arguments. This would demand a re-evaluation of water and finally an economic anticipation of the potential environmental benefits of wastewater reuse.

How to investigate the optimal or simply the most acceptable allocation of reclaimed water will be a crucial element in any wastewater reuse strategy as each of the options will demand specific use-dependent incentives that might even differ from case to case.

It will be a future task to adjust the model variables, especially the reuse-factor, taking into account its sensitivity to influences like regulatory constraints, pricing mechanisms and similar.

\section{Acknowledgements}

The presented research has been carried out within the AQUAREC (EVK1-CT2002-00130) project which is funded by the European Commission as part of the 
implementation of Key Action 1 "Sustainable Use of Water" within the Energy, Environment and Sustainable Development Thematic Programme of the $5^{\text {th }}$ Framework Programme.

\section{References}

[1] Australian Academy of Technological Science and Engineering, (Ed.),Water Recycling in Australia, 2004

[2] Barry Rubin (ed.), Efficient use of limited water resources: Making Israel a Model State, BESA Books, 2001

[3] Department of Water Resources, Water Recycling 2030 - Recommendations of California’s Recycled Water Task Force, Sacramento, 2003

[4] Geonardo, www.geonardo.hu - Project partner in AQUAREC

[5] Ministerio de Medio Ambiente (MMA). Libro Blanco del agua en Espana., Madrid, Spain, 2000

[6] S. Barbagallo, G.L. Cirelli, S. Indelicato, Wat. Sci. Tech., 43 (10), (2001), 4350. Wastewater reuse in Italy.

[7] R. Hochstrat, T. Wintgens, T. Melin, P. Jeffrey. Proceedings of the IWA World Water Congress (2004) Wastewater reclamation and reuse in Europe - a modelbased potential estimation,

[8] D. Bixio, B. de Heyder, D. Joksimonovic, H. Chikurel, V. Miska, M. Muston and C. Thoeye. Proceedings of the IWA World Water Congress (2004) Municipal wastewater reclamation: Where do we stand? An overview of treatment technology and management practice.

[9] B. Lehner, T. Henrichs, P. Döll, J. Alcamo, EuroWasser - Model-based assessment of European water resources and hydrology in the face of global change. Kassel World, (Water Series 5, Center for Environmental Systems Research, University of Kassel, Germany 2001)

[10] EEA (Ed.) Water resources problems in southern Europe - An overview report, Kopenhagen, Denmark(1996)

[11] EEA (1999b). Sustainable water use in Europe - Part 1: Sectoral use of water. Environmental Assessment Report No. 1. European Environment Agency, Copenhagen

[12] INAG Plano Nacional da Água. Instituto da Água. Lisbon, Portugal(2002).

[13] Kamizoulas, G., Bahri, A., Brissaud, F., Angelakis, A.N. (2003). Wastewater recycling and reuse practices in Mediterranean region: Recommended guidelines. Published on www.med-reunet.com

[14] I.A.Shiklomanov, World water resources and their use. Database at: UNESCO, International Hydrological Programme, 1998.

[15] J.A. de la Orden-Gómez, JM Murillo. Recharge enhancement to prevent saltwater intrusion in coastal Spain Proc. ISAR-4, Adelaide Sept. 2002

[16] Ministry of Agriculture, Natural Resources \& Environment, Water Development Department, Use and Conservation of Water in Cyprus, 2002 
[17] MoE-PL (1997). Report on the State of the Environment in Poland. Ministry of Environment. available at: http://www.mos.gov.pl/soe/)

[18] Waterbase, European Environment Agency (EEA) http://dataservice.eea.eu.int/dataservice/metadetails.asp?id=646 